\title{
Index of writings by Charles Olson
}

'3rd letter on Georges, unwritten' 136 King of the Wood 287-8

'A Bibliography on America for Ed Dorn' 135, 139

'a Plantation a beginning' 128

'ABCs' 89

'ABCs (3-for Rimbaud)' 60

'An Ode on Nativity' 115-16

Apollonius of Tyana 288, 291-2

Archaeologist of Morning 115, 265

'As the Dead Prey Upon Us' 17-18, 48, 182, Chapter 15 passim

'Ballad for Americans' 89

Call Me Ishmael 1, 29, 32, 55-6, 113, $115,117,128,149-50,159$, $163,164-70,185,219,273,302$

'Causal Mythology' 89, 250 n.45,

'Credo' 92

'For Sappho, Back' 157

'Help Me, Venus, You Who Led Me On' 157

'Human Universe' 12, 26, 27, 38, 52, 54, 91, 92, 198, 209, 215, 217-18, 222, 225, 228, 240, $248,267,272,286$

'I, Maximus of Gloucester, to You' 157

'In Cold Hell, in Thicket' 15, Chapter 4 passim, 103-7, 110, 114, 129, 157, 159, 209, 273

'Letter 22' 48

'Letter for Melville 1951' 89

'Letter to Elaine Feinstein' 1, 28, 114, 151, 185, 245

Letters for Origin 115

'Maximus, at Tyre and at Boston' 283

'Maximus, to Gloucester: Letter 2' 9

'Maximus, to Gloucester, Letter 27 [withheld]' 44, 110

Maximus, from Dogtown 181

'Maximus, from Dogtown-I' 61

'Maximus, from Dogtown-II' 28, 61,300

'Maximus, to Gloucester: Letter 15' 16, Chapter 7 passim, 120

Mayan Letters 129, 130, 140, 209, 265, 267

'Projective Verse' 1, 2-3, 10, 11, 14-15, 18, 26, 38, 40, 41-2, $59-60,62,65,78,79,80,82$, $84,89,91,97,98,105-6,113$, 127, 140, 149, 151-5, 157, 170, 185, 190, 209, 229, 246, Chapter 20 passim, 301

'Quantity in Verse, and Shakespeare's Late Plays' 121

'The Advantage' 153, 157 
The Born Dancer 288

The Distances 181

'The Gate and the Center' 159, 195, 223, 269, 271

'The Kingfishers' 1, 3-6, 18, 83, $85,103-4,106-7,120,129$, 130, 153, 155, 156, 199-200, 209, 210, Chapter 18 passim, Chapter 19 passim, 273-4, 283

'The Librarian' 48, 120, 182

'The Lordly and Isolate Satyrs' 17, Chapter 13 passim

The Maximus Poems 3, 4, 8, 9, 10, 18, 19, Chapter 1 passim, $44,48,53,57,61,91,110$,
111-12, 114-15, 116, 127, 128, Chapter 10 passim, 149, 151, 155, 156, 182, 200, 206, Chapter 17 passim, 272, 274-5, 279, 281-5, 300, 305, 308

The Special View of History 4, 5, 8, 27, 52, 216, 228, 240, 241, $272,275,277,278-9,281$

'The Twist' 48, 49, 120,

'These Days' 157

West 115, 297

$Y$ \& $X 1,64,156$ 